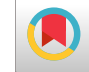

\title{
Formulation of Triple Cream for Treatment of Melasma
}

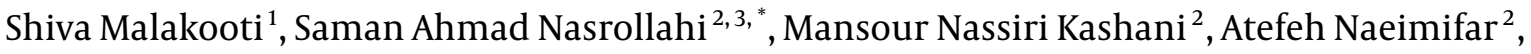 \\ Fatemeh Amiri $^{2}$, Hossein Rastegar ${ }^{3}$ and Alireza Firooz ${ }^{2,3}$ \\ ${ }^{1}$ Pharmaceutical Sciences Branch, Islamic Azad University, Tehran, Iran \\ ${ }^{2}$ Pharmaceutical, Cosmeceutical and Hygienic Formulation Lab, Center for Research \& Training in Skin Diseases \& Leprosy, Tehran University of Medical Sciences, Tehran, Iran \\ ${ }^{3}$ Cosmetic Products Research Center, Food \& Drug Organization, MOH \& ME, Tehran, Iran \\ "Corresponding author: Ph.D., Center for Research \& Training in Skin Diseases \& Leprosy (CRTSDL), Tehran University of Medical Sciences (TUMS), No. 415, Taleqani Ave., Tehran, \\ Iran. Tel: +98-2188963804, Fax: +98-2188963804, Email: snasrollahi@tums.ac.ir \\ Received 2017 September 27; Revised 2018 May 20; Accepted 2018 August 28.
}

\begin{abstract}
Background: Melasma is a common disorder of hyperpigmentation affecting the face that is associated with considerable psychological impacts. The management of melasma is challenging and requires a long-term treatment plan. Therapeutic goals for hyperpigmentation include the destruction of melanosomes, inhibition of the melanocyte formation, and delay in the spread of melanocytes. Hydroquinone is a commonly used treatment for melasma, but it is combined with other medications due to its low efficacy in single therapy and relapse. Hydroquinone is hydroxy phenol which inhibits melanin by inhibiting tyrosinase. In addition, retinoid is effective in treating melasma and stimulate the cycle of skin cells, thus increasing the rate of loss of color pigmentation. A corticosteroid is used to increase the efficacy of these two drugs.

Objectives: The purpose of this study is to formulate an integrated formulation for the treatment of this skin disease.

Methods: The triple cream, which is a combination of hydroquinone (HQ), tretinoin(TRE), and fluocinolone acetonide(FLU) demonstrate better efficacy in decreasing skin pigmentation due to the additive and synergistic effects of these ingredients. As there is no topical generic formulation in combined form in Iran, such cream is prepared that contains $4 \% \mathrm{HQ}, 0.05 \%$ TRE and $0.01 \%$ FLU as an oil in water $(\mathrm{O} / \mathrm{W})$ cream.

Results: The result of this study was a 6-month accelerated evaluation of physical and physicochemical properties, including pH, electrical conductivity, density, viscosity, active ingredient identification, determination of amount and completely stable and homogeneous microbial tests. A review of the identification of the active ingredient and the determination of the amount conformed to the USP standard (American Pharmacopoeia). Also, material release from the base was well done.

Conclusions: The prepared cream was completely stable and homogeneous during the accelerated conditions by evaluating of physicochemical and microbial assessments.
\end{abstract}

Keywords: Fluocinolone, Hydroquinone, Melasma, Tretinoin

\section{Background}

Melasma is the overproduction of melanin in the skin and came from the Greek translate of phrase black (Melas). Melasma is one of the most popular, therapyresistant types of acquired hyperpigmentation. The risk of melasma infliction in females is nine times more than males, and it is more often in darker-skinned individuals, such as Hispanics, Asians, or other racial groups (1). Melanocytes create melanin pigment and the increase in melanin may be due to both a proliferation in melanogenesis and melanocytosis. The contributing factors in melasma pathogenesis include genetics, hormones, and UV radiation. Other implicated factors include the use of certain cosmetics, phototoxic drugs, and anticonvulsant medication. Lots of long-term treatment plan of melasma shows non-effective procedure. Therefore, it is a challenging disease (2).

Bleaching creams are a common OTC or prescribed products used to whiten the skin color spots. These creams contain various active ingredients such as hydroquinone (HQ), glycolic acid, azelaic acid, kojic acid, corticosteroids, tretinoin (TRE) and lots of herbal extracts (3). Based on the cost/benefit analysis (4), the triple combination therapy is the most effective primary treatment for melasma rather than monotherapy (4). The combination of HQ, TRE, and topical steroids can provide better therapeutic outcomes (as they work with different mechanisms of inhibition of melanogenesis) and also can be tolerated by patients (5). The HQ is the main treatment for melasma but has relatively low effectively as monotherapy, and re-

Copyright (c) 2019, Jundishapur Journal of Natural Pharmaceutical Products. This is an open-access article distributed under the terms of the Creative Commons Attribution-NonCommercial 4.0 International License (http://creativecommons.org/licenses/by-nc/4.0/) which permits copy and redistribute the material just in noncommercial usages, provided the original work is properly cited. 
currences are common. This ingredient was originally believed to act mainly by inhibition of tyrosinase of epidermal melanocytes because of its structural analogy to melanin precursors.

The whitening effect of HQ is seen after 2 to 3 weeks of daily use (6). Its efficacy as a depigmenting agent is influenced by several parameters, such as concentration, chemical stability, and vehicle of administration. The highest concentration of HQ is more effective, but it may cause dermatitis. Making HQ into a stable preparation is challenging because of the highly reactive oxidative nature of the agent, changing from creamy white to a darker brown via oxidation. The penetration of enhancers such as TRE or alpha hydroxyl acids enhances the timed delivery of HQ to the skin (7). The first time, TRE was used in hyperpigmentation by Kligman in 1975 . His statement showed that patients who getting TRE developed lighter skin after months of applications. In fact, TRE acts by preventing the oxidation of HQ, improving stratum corneum penetration, allowing pigment elimination, and increasing keratinocyte proliferation. As a result, TRE is commonly combined with one or two other agents to accelerate the beneficial effect (8).

Triple combination also contains a corticosteroid. It is believed that corticosteroid can inhibit melanin synthesis by decreasing cellular metabolism. Furthermore, corticosteroids reduce the irritation or inflammation caused by HQ and TRE. In 1975, Kligman and Willis used 0.1\% dexamethasone in combination with 5\% HQ and 0.1\% TRE (9). After that, scientists found out steroids containing fluorine were more effective than nonfluorinated ones. Therefore, $0.01 \%$ fluocinolone acetonide (FLU) was used instead of dexamethasone, then HQ and TRE were reduced to $2 \%$ $4 \%$ and $0.05 \%$, respectively (3). Now in the US, the pharmaceutical formulation of this triple-combination was sold under the brand name of Tri-Luma (Galderma Co.) $(4,10$, 11). Although combination therapy shows an acceptable efficacy, multi-active formulas are unstable both in physical and chemical reactions. Parameters such as phase separation, solubility, oxidation, assay, content uniformity and etc. are important (12). To the best of our knowledge, there is no study about the formulation type and stability tests of triple bleaching creams. Neither method has been mentioned in the United States pharmacopeia. In this research, we formulated and examined physico-chemical properties of a triple combination of HQ 4\%, TRE 0.05\%, and FLU $0.01 \%$.

Side effect of HQ is skin irritation, dryness, erythema, and dermatitis. Common side effects of topical TRE include warmth or stinging immediately after applying the medication. Other side effects of TRE include skin tingling, itching, redness, swelling, dryness, peeling, and irritation during the first 2 - 4 weeks of using the medication. Common side effects of FLU include burning, stinging, itching, dryness, peeling, and redness. These side effects should disappear in a few days as your body adjusts to FLU.

\section{Methods}

The HQ was obtained from Medilux (India), TRE was procured from Olon (Italy) and FLU was purchased from Farmabios (Italy). Glycerol stearate and PEG-100 stearate and caprylic/capric acid triglyceride were bought from Croda (UK), cetearyl alcohol, glycerin, methylparaben, propylparaben, sodium metabisulfite (MBS), and ascorbic acid were purchased from Merck (Germany). Deionized water was produced freshly whenever required. A lipid phase containing FLU, TRE, glycerol stearate and PEG-100 stearate, caprylic/capric acid triglyceride and cetearyl alcohol, totally $25 \%$, as well as $75 \%$ aqueous phase composed of HQ, ascorbic acid, glycerin and methylparaben, propylparaben, MBS, and deionized water.

\subsection{Preparation of Triple Cream}

To prepare a triple cream, we used a lipid phase containing FLU, TRE, glycerol stearate and PEG-100 stearate, caprylic/capric acid triglyceride and cetearyl alcohol, as well as an aqueous phase composed of HQ, ascorbic acid, glycerin and methylparaben, propylparaben, sodium metabisulfite (MBS), and deionized water. The Aqueous phase was heated up to $75^{\circ} \mathrm{C} \pm 1^{\circ} \mathrm{C}$. Oily phase was heated to the same temperature. Then oil in water $(\mathrm{O} / \mathrm{W})$ cream was prepared by the adding of the oily phase to the aqueous phase with nonstop stirring at 600 rpm (IKA, Germany) until it was cooled down to the room temperature. This formulation must be kept in the refrigerator at $5 \pm 3^{\circ} \mathrm{C}(13,14)$.

\subsection{Stability Studies}

The manufactured cream was passed 6 months accelerated stability tests at $25 \pm 2{ }^{\circ} \mathrm{C} / 60 \pm 5 \% \mathrm{RH}$. During this period, physical and chemical analysis was done at 1st, 2nd, 3rd, and 6th months as mentioned in ICH stability guideline (15).

\subsection{Physical Parameters}

The prepared cream was examined visually for color, odor, homogeneity, consistency, phase separation.

\subsection{Emulsion Type}

An electrical conductivity test was conducted by conductivity meter to determine the type of emulsion. In this test, the sample was diluted with deionized water. If the emulsion is completely soluble in deionized water and forms a diluted homogeneous emulsion, the emulsion is $\mathrm{O} / \mathrm{W}$ and vice versa (16). 


\subsection{Density}

The density, or more precisely, the volumetric mass density, of a substance is its mass per unit volume. The exact volume of pycnometer was determined by filling it fully with water and was tapped the sides gently to remove the air bubbles. The flask was weighted full of a cream, then easily the density was calculated (dividing mass by volume).

\subsection{Determination of $\mathrm{pH}$}

To this end, $2 \pm 0.01 \mathrm{~g}$ of cream was dispersed in a 50 $\mathrm{mL}$ beaker containing $18 \mathrm{~mL}$ water. Then $\mathrm{pH}$ was determined in $25 \pm 2^{\circ} \mathrm{C}$ by pH meter (Metrohm 827, Swiss) (17).

\subsection{Viscosity}

The viscosity of cream was measured by Polyvisc Viscometer (Instrumentacion Cientifica Tecnica, Spain) using spindle R7 at 100 RPM with the run time of 1 minute. Viscosity determinations were performed at room temperature $\left(25 \pm 2^{\circ} \mathrm{C}\right)(17)$.

\subsection{Identification of Active Ingredients}

For identification of $\mathrm{HQ}$, a portion of cream equivalent to about $50 \mathrm{mg}$ of HQ was dissolved in a mixture of chloroform and methanol to make $50 \mathrm{~mL}$ dispersion, then was read in TLC paper and compared with the standard. The retention time of the major peak in the chromatogram of the assay preparation corresponding to that in the chromatogram of the standard preparation was obtained as directed in the assay of TRE. At least for FLU, a quantity of cream equivalent to about $0.5 \mathrm{mg}$ of FLU was dissolved, and centrifuged with water and chloroform (1:2), then the aqueous layer was removed and sodium sulfate $100 \mathrm{mg} / \mathrm{mL}$ was added. The extract was responded to TLC and then compared with standard solutions.

\subsection{Assay of Active Ingredients}

\subsubsection{Hydroquinone (HQ)}

An accurately weighed portion of cream, equivalent to about $20 \mathrm{mg}$ of $\mathrm{HQ}$, was moved to a $100 \mathrm{~mL}$ beaker, which contained $50 \mathrm{~mL}$ methanol to triturate. Seventy-five $\mathrm{mL}$ of methanol was added to $25 \mathrm{~mL}$ of the sample solution and mixed. Concomitantly the absorption of the standard preparation and the assay preparation were determined at the wavelength of maximum absorbance at 293 $\mathrm{nm}$, with an appropriate spectrophotometer (Cecil 2501United Kingdom).

\subsubsection{Tretinoin (TRE)}

An accurately weighed amount of cream, equivalent to $1 \mathrm{mg}$ of TRE, was moved to a $50 \mathrm{~mL}$ volumetric flask, and added $20 \mathrm{~mL}$ of tetrahydrofuran. $5 \mathrm{~mL}$ of this solution was transferred to a $25 \mathrm{~mL}$ volumetric flask, diluted with a mixture of tetrahydrofuran and diluting solution (prepared a mixture of water and dilute phosphoric acid 10\%) (3:2) to volume. The separatists were injected equivalent volumes (about $25 \mu \mathrm{L}$ ) of the standard preparation and the assay preparation into the chromatograph, the chromatograms were verified at $352 \mathrm{~nm}$.

\subsubsection{Fluocinolone Acetonide (FLU)}

An accurately weighed portion of cream, equivalent to about $0.75 \mathrm{mg}$ of the FLU, was dissolved in about $10 \mathrm{~mL}$ acetonitrile. The mixture to $25 \mathrm{~mL}$ volumetric flask was transferred with the aid of three portions of $2 \mathrm{~mL}$ acetonitrile. A mixture of water and acetonitrile (5:3) was prepared for mobile phase. Chromatograph equal volumes of the assay preparation and the standard preparation at $254 \mathrm{~nm}$. Three repeated injections of the standard preparation were shown as a resolution factor of not less than 2 between the peaks for norethindrone and FLU and a relative standard deviation of not more than $1.5 \%$.

\subsection{Assay of Preservative (Parabens)}

Approximately $5 \mathrm{~g}$ of cream was weighed in a $500 \mathrm{~mL}$ glass tube with screw cap. Five $\mathrm{mL}$ sulfuric acid solution (4/9) and $50 \mathrm{~mL}$ ethanol/water mixture (4/10) were transferred to the tubes. The tube was kept for five minutes in a water bath at $60 \pm 1^{\circ} \mathrm{C}$ to facilitate the extraction of the preservatives into the ethanol phase. The extraction tube was rinsed with an ethanol/water mixture (4/10). A mixture of water/acetonitrile mixture (4/11) was prepared for mobile phase. Chromatograph equal to the assay preparation and the standard preparation was screened at $254 \mathrm{~nm}$. Methylparaben must be between $0.144 \%$ (NLT) and $0.216 \%$ (NMT). Propylparaben must be in the range of $0.016 \%$ and $0.024 \%$

\subsection{Microbial Assessments}

Ten $\mathrm{g}$ of cream was mixed with $3 \mathrm{~g}$ of sterile tween 80 , then $24 \mathrm{~g}$ of $10 \%$ tween 60 water solution was added to TSB medium to diagnose the bacteria (Mixture A). Plates having 25-250 colonies were counted and the average number of CFU/g was calculated. Two dilutions $\left(10^{-1}, 10^{-2}\right)$ with the TSB culture medium were prepared and 1- $2 \mathrm{~mL}$ of premed dilution was added to 2 sterile plates containing $10-20 \mathrm{~mL}$ of TSA culture medium, and incubated for 24 - 48 hours at $30-35^{\circ} \mathrm{C}$ (Pure plate). One $\mathrm{mL}$ of 0.1 dilution for fungal counting allowed the agar to solidify at room temperature, then for $5-7$ days incubated at $20-25^{\circ} \mathrm{C}$. Colonies 
were counted after the incubation and all operations were carried out in duplicate. All microbial counts were transformed into logarithms of the number of colony-forming units $(\log 10 \mathrm{CFU} / \mathrm{g})$. Counting was passed in plates that contain less than 100 colonies for microbial count (TAMC) and contain less than 10 colonies for fungal count (TYMC) $(18,19)$.

\subsection{Pseudomonas aeruginosa Count}

Colonies of P. aeruginosa were counted after $24-48$ hours of incubation at $30-35^{\circ} \mathrm{C}$.

\subsection{Staphylococcus aureus Count}

Colonies of S. aureus were nominated, gram-stained, and observed for oxidase and catalase reactions to confirm their presence (18).

\subsection{Yeast and Mold Counts}

After the incubation period, the presence of white colonies and their confirmation with differential tests such as tuberculosis was confirmed by Candida albicans.

\subsection{Preservative Effectiveness Test}

A standardized inoculum containing 3 bacteria (S. aureus, E. coli, and $P$. aeruginosa), a yeast (C. albicans) and a mold (Aspergillus niger) was mixed with the liquid product. The mixture containing $0.05 \%$ of polysorbate 80 , and add sufficient sterile buffer phosphate ( $\mathrm{pH}: 7.2)$ to gain a count of about $1 \times 10^{8} \mathrm{CFU}$ per $\mathrm{mL}$. The absorption of this inoculum was read at $580 \mathrm{~nm}$. Ten $\mathrm{g}$ of cream was added to 90 cc buffer phosphate (Mixture $\mathrm{B}$ ) and $10^{1}$ and $10^{2}$ dilutions of the mixture $B$ was made. Then, $1 \mathrm{~mL}$ of $10^{1}$ and $10^{2}$ dilutions was added to a sterile plate containing $15-20 \mathrm{~mL}$ of TSA medium, which cooled to $45^{\circ} \mathrm{C}$, and incubated for 24 - 48 hours at $30-35^{\circ} \mathrm{C}$. The fungal method was similar to the above except that the SDA culture with $10^{1}$ dilution was incubated for $5-7$ days at $20-25^{\circ} \mathrm{C}$. Positive and negative controls were used during the experiment. Microbiological tests were repeated for formulations at $25^{\circ} \mathrm{C}$ after 14 and 28 days of the preparation (19).

\subsection{In Vitro Release Studies}

In vitro release of $\mathrm{HQ}, \mathrm{TRE}$, and FLU from formulation was evaluated by using cellulose nitrate membrane $(0.45$ micron). The membrane was mounted on modified Franz diffusion cells with a surface of $12.56 \mathrm{~cm}^{2}$ and a receptor volume of $34 \mathrm{~mL}$. The receptor compartment was nonstop stirred at 100 RPM using the magnetic stirrer. The receptor phases for HQ, TRE, and FLU were methanol, isopropyl alcohol, and acetonitrile, respectively. Then, $0.5 \mathrm{~g}$ of the formulations was applied with a spatula in the donor compartment and the diffusion cells protected with an aluminum foil to avoid light exposure. The temperature was maintained at $37.0 \pm 1^{\circ} \mathrm{C}$ by a water jacket. Sampling was done at 30, 60, 120, 180, and 240 minutes, and at each point, 3 $\mathrm{mL}$ aliquots were drawn from the receiver section. After that, an equivalent volume of suitable receptor fluid was put back to the receiver compartment to save sinking conditions. The profile of release was then designed. Samples were analyzed with a UV spectrophotometer (Wavelengths of $293 \mathrm{~nm}$ for HQ, $352 \mathrm{~nm}$ for TRE and $254 \mathrm{~nm}$ for FLU) (20, 21).

\section{Results and Discussion}

An effective treatment for epidermal melasma is a combination of HQ, a steroid, and TRE. The combination strongly inhibits the production of melanin without the harmful damage of melanocytes. Kligman and Willis recommended a preparation containing HQ 5\%, TRE 0.1\%, and dexamethasone 21 -acetate $0.1 \%$, to be applied daily for 5 to 7 weeks, and it was found to be effective in the treatment of melasma. Despite its effectiveness, this preparation contains high concentrations of TRE and HQ, and holds dexamethasone, which is a potent fluorinated steroid. Dexamethasone and betamethasone (steroids 9- $\alpha$ fluorine) have no advantage over FLU. Indeed, FLU (acetonide derivatives from fluorine steroids) is superior in the treatment of hyperpigmentation. In FLU, halogenation in the 9- $\alpha$ position increases the strength by improving the target cell activity and reducing the conversion to inactive metabolites. Also, covering or removing the hydrophilic part in the position of 17 dihydroxy acetonide or 16- $\alpha$-hydroxy, increases the lipophilicity of the molecule and thus increases the penetration of stratum corneum $(22,23)$.

A cream containing HQ 4\%, TRE 0.05\%, and FLU 0.01\% applied daily for 8 weeks was more effective than other formulations (5). In this formula, lowering the concentrations of the components reduced the frequency of irritancy. Because of HQ and TRE, this triple compound cream susceptible to instability (e.g. phase separation, change color, and decrease of assay). In this study, we prepared a stable generic pharmaceutical product with an appropriate analysis method $(5,24)$.

The freshly prepared cream had a yellow light color and homogenous texture. In order to find the emulsion type, the dilution test by distilled water depicted $\mathrm{O} / \mathrm{W}$ structure. In addition conductivity assessment of this formulation by conductivity meter showed an electrical conductivity of 0.41 milliseconds which confirmed $\mathrm{O} / \mathrm{W}$ system. As the control paraffin showed zero electrical conductivity. Finally, microscopic images demonstrated the dispersion of oil droplets in the aqueous media (Figure 1). 
Our triple cream was exposed to the stability study as per ICH guidelines for a period of six months. It was checked at $25 \pm 2^{\circ} \mathrm{C} / 60 \pm 5 \%$. During the period of storage, the formulation showed no variation in color, odor, $\mathrm{pH}$, and phase separation (Table 1). As shown in Table 1 , the mean $\mathrm{pH}$ at the initial, 1st, 2nd, 3rd, and 6th months was $5.2,5.4,5.7,5.6$, and 5.7, respectively. The viscosity at the initial, 1st, 2nd, 3rd, and 6th months was 13325, 14429, 15670, 17688 , and 17148 cp one by one. Finally, the density of fresh cream was 0.99174 , and at 1st, 2nd, 3rd, and 6th months was 0.9952, 0.9960, 0.99 and 0.994, respectively. A microbial assessment at the initial, 1st, 2nd, 3rd, and 6th months was $7,0,0,2$, and 0 colonies, and fungi counts was $1,0,0,0$, and 0 colonies, respectively, indicating that antimicrobial activity has been adequate and efficient.

The assay of active pharmaceutical ingredients in the formulation was desirable. As shown in Figure 2, in HPLC results, the retention time of FLU was in 3.7 minutes, the retention time of Norethindrone (standard of FLU) was in 6.5 minutes, the retention time of TRE was in 1.2 minutes, the retention time of methylparaben and propylparaben was in 2.5 and 4.5 minutes, respectively. Therefore, as shown in Table 1, the percent of assay of HQ, TRE, and FLU at the initial, 1st, 2nd, 3rd, and 6th months were found in range. The percent of assay of HQ was 99.80, 99.71, 99.15, 99.50, and 99.25 at initial, 1st, 2nd, 3rd, and 6th months, respectively. The percent of the assay of TRE was 98.52, 98.23, 98.91, 98.00, and 98.15 at 1st, 2nd, 3rd, and 6th months, respectively. The percent of assay of FLU was 106.4, 105.6, 104.75,

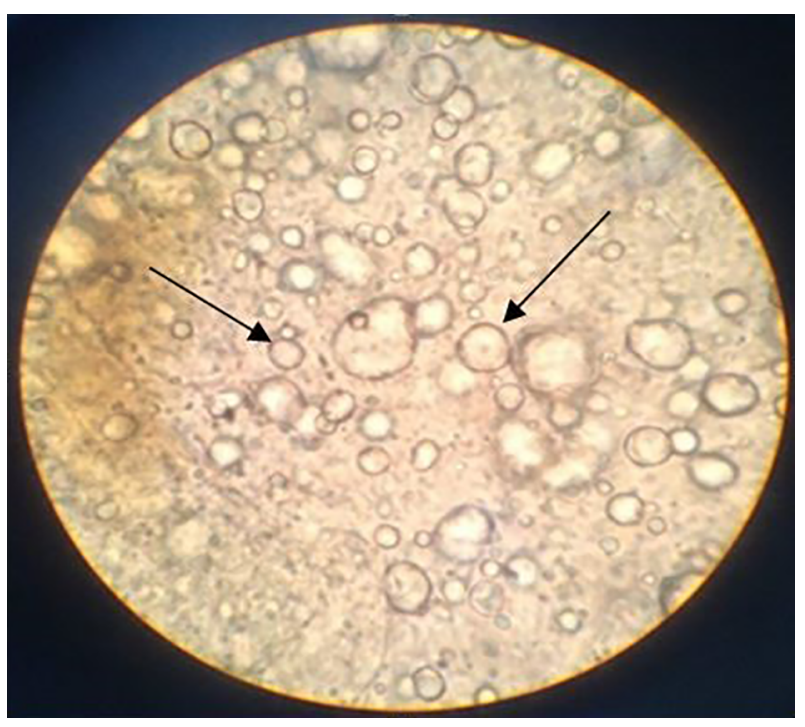

Figure 1. The microscopic image of the emulsion shows the dispersion of oil droplets (arrows) in water

Jundishapur J Nat Pharm Prod. 2020;15(2):e62252.
102.89 and 103.26 at 1 st, 2nd, 3rd, and 6th months, respectively. In addition, preservatives were at the desirable antimicrobial activity range. The percent of assay of methylparaben was $0.112,0.108,0.107,0.106$, and 0.109 at the initial, 1st, 2nd, 3rd, and 6th months, respectively. The percent of assay of propylparaben was 0.013, 0.010, 0.012, 0.010 and 0.011 at the initial, 1st, 2nd, 3rd, and 6th months, respectively.

In vitro diffusion studies reveals that our formulation showed a proper drug permeation into cellulose nitrate membrane and good release of all actives within 120 minutes, which may reflect a reliable therapeutic effect of formulation. As depicted in Figure 3, at the time of 90 minutes, FLU was $100 \%$ released from the cream basement. The HQ was reached with the maximum release of $71 \%$ at 40 minutes and TRE was shown a sustained release during 100 minutes to obtain nearly $100 \%$ release. Many commercial TRE topical formulations deliver all TRE in half an hour, which causes skin irritations. In this triple cream, slow and constant release of TRE in the first 60 minutes, in combination with the fast release of FLU as an anti-inflammatory agent, suggests minimum skin erythema, peeling, and dryness.

\section{Conclusion}

Melasma treatment can be challenging and require long-term treatment with topical agents. Melasma may be cured using monotherapy or combination therapy. These therapies, joined with regular application of a UVA and UVB blocking sunscreen to avoid UV-induced recurrence, are the most common therapies for epidermal melasma. A triple combination of HQ, TRE, and FLU has been counseled to be the first-line topical treatment for this pigmentary condition. In this study, for the first time in Iran, we loaded three sensitive active agents in one emulsion without any phase separation, oxidation, and active's potency loss. We recommend this new depigmenting combination as a generic pharmaceutical cream would be useful for melasma as well as other indications such as after dermalesthetic procedures.

\section{Acknowledgments}

This study was supported by research grant number 93-04-34-27706 from Center for Research and Training in Skin Diseases and Leprosy, Tehran University of Medical Sciences. The technical help of Dr. Azadeh Moradi and Mr. Vahid Mahmoudi in the preparation and analytical evaluation of the final cream is appreciated. 
A

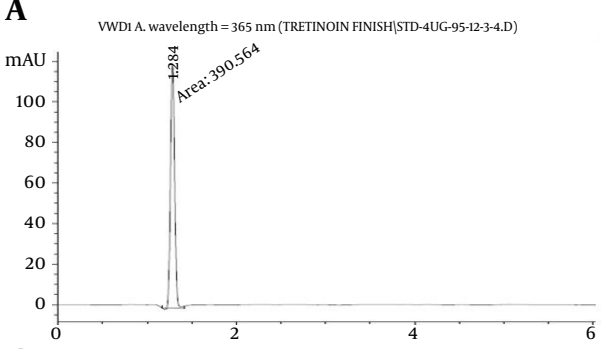

C

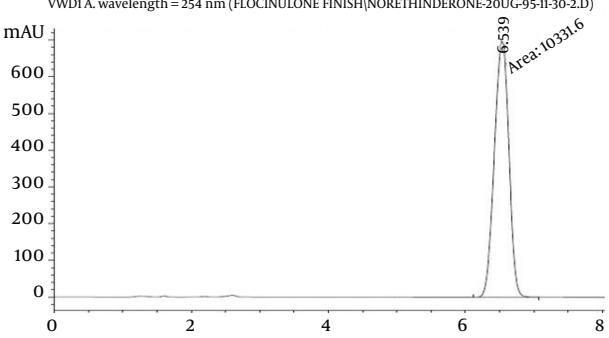

B

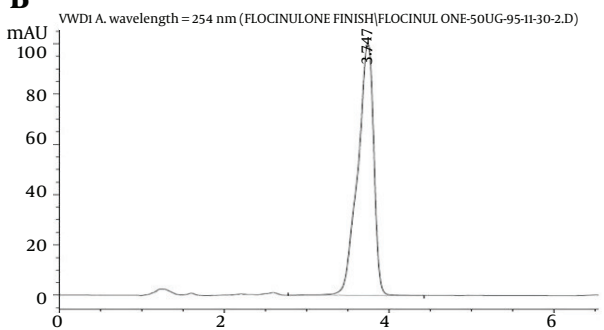

D

VWDI A. wavelength $=254 \mathrm{~nm}$ (FLOCINULONE FINISH|STANARD PREPARATION-4.D)

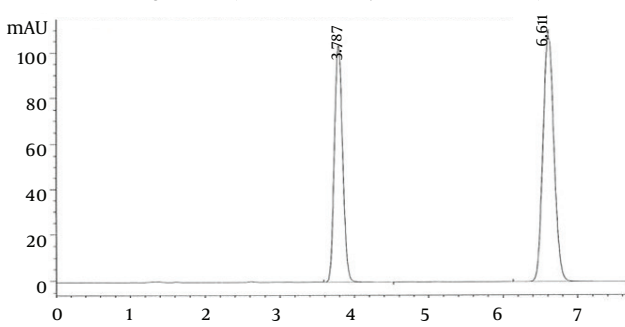

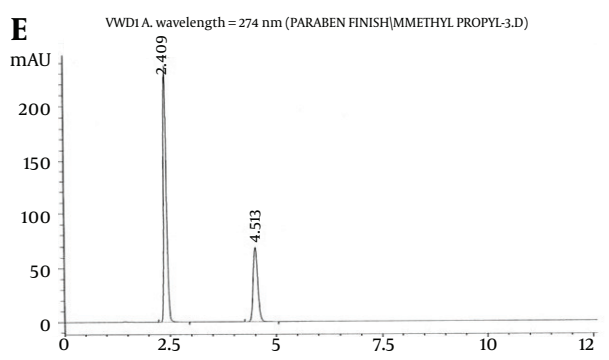

Figure 2. HPLC assay of A, TRE; the retention time of this substance is in 12 minute; $B$, FLU; retention time of this substance is in 3.7 minutes: $C$, Norethindrone (standard of FLU), the retention time of this substance is in 6.5 minutes; D, both FLU and Norethindrone in one injection; E, methyl paraben and propyl paraben, the retention time of methylparaben is in 2.5 minutes and propyl paraben is in 4.5 minutes.

\section{A}

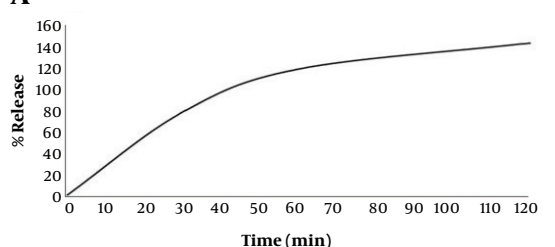

Time (min)
B

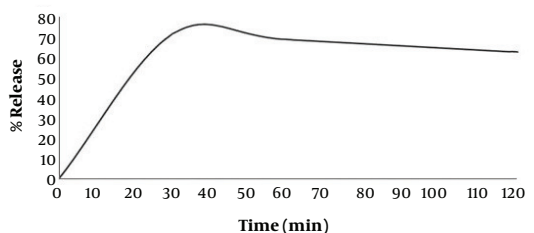

C

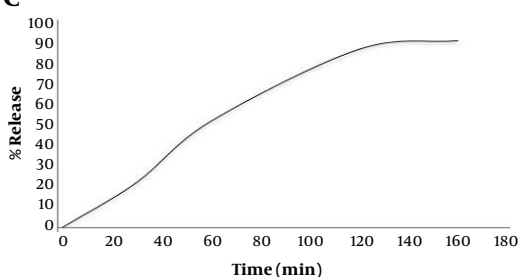

Figure 3. In vitro penetration and cumulative drug release of A, FLU; B, HQ; C, TRE; permeated through cellulose nitrate membrane 


\begin{tabular}{|c|c|c|c|c|c|c|}
\hline \multirow{2}{*}{ Test } & \multicolumn{5}{|c|}{ Period of Storage } & \multirow{2}{*}{ Standard } \\
\hline & Initial & 1st M & 2nd $M$ & 3rd M & 6th M & \\
\hline Description & Complies & Complies & Complies & Complies & Complies & Yellow light cream, homogenous cream mass \\
\hline Odor & Complies & Complies & Complies & Complies & Complies & Characteristic odor \\
\hline $\mathbf{p H}$ & 5.2 & 5.4 & 5.7 & 5.6 & 5.7 & NLT 5.00; NMT 6.00 \\
\hline Viscosity (cp) & 13325 & 14429 & 15670 & 17688 & 17148 & NLT 13000; NMT 18000 \\
\hline Density $\left(\mathrm{g} / \mathrm{cm}^{3}\right)$ & 0.99174 & 0.9952 & 0.9960 & 0.99 & 0.994 & NLT 0.980; NMT 0.999 \\
\hline \multicolumn{7}{|l|}{ Assay (g/100 g cream) } \\
\hline HQ & 99.80 & 99.71 & 99.15 & 99.50 & 99.25 & $94-106 \%$ \\
\hline TRE & 98.52 & 98.23 & 98.91 & 98.00 & 98.15 & $90-120 \%$ \\
\hline FLU & 106.4 & 105.6 & 104.75 & 102.89 & 103.26 & $90-110 \%$ \\
\hline Methyl paraben & 0.112 & 0.108 & 0.107 & 0.106 & 0.109 & $0.05-0.2 \%$ \\
\hline Propyl paraben & 0.013 & 0.010 & 0.012 & 0.010 & 0.011 & $0.01-0.04 \%$ \\
\hline Identification & Approved & Approved & Approved & Approved & Approved & $\begin{array}{l}\text { The chromatograms of assay preparation and } \\
\text { standard preparation exhibit the same major } \\
\text { peak for cream }\end{array}$ \\
\hline \multicolumn{7}{|l|}{$\begin{array}{l}\text { Microbial enumeration \& tester for } \\
\text { specific microorganism }\end{array}$} \\
\hline Total bacterial count $(\mathrm{CFU} / \mathrm{g})$ & 7 & 0 & 0 & 2 & 0 & NMT 100 \\
\hline Total fungi \& yeast count (CFU/g) & 1 & 0 & 0 & 0 & 0 & NMT 10 \\
\hline P. aeruginosa & Neg. & Neg. & Neg. & Neg. & Neg. & Must be negative \\
\hline S. aureus & Neg. & Neg. & Neg. & Neg. & Neg. & Must be negative \\
\hline E. coli & Neg. & Neg. & Neg. & Neg. & Neg. & Must be negative \\
\hline Antimicrobial effectiveness test & Ok & Ok & Ok & Ok & Ok & $\begin{array}{l}\text { Bacteria: Not less than } 2 \text { log reduction from } \\
\text { the initial count of } 14 \text { days, and no increase } \\
\text { from } 14 \text { days' count at } 28 \text { days. Yeast and } \\
\text { mold: No increase from the initial calculated } \\
\text { count of } 14 \text { and } 28 \text { days. }\end{array}$ \\
\hline Remark/conclusion & Approved & Approved & Approved & Approved & Approved & \\
\hline
\end{tabular}

Abbreviations: HQ, hydroquinone; TRE, tretinoin; FLU, fluocinolone.

\section{Footnotes}

Conflict of Interests: The authors declare no conflict of interest.

Funding/Support: This study was supported by research grant number 93-04-34-27706 from Center for Research and Training in Skin Diseases and Leprosy, Tehran University of Medical Sciences.

\section{References}

1. Halder RM, Nootheti PK. Ethnic skin disorders overview.JAm Acad Dermatol. 2003;48(6 Suppl):S143-8. doi: 10.1067/mjd.2003.274. [PubMed: 12789168].

2. Prignano F, Ortonne JP, Buggiani G, Lotti T. Therapeutical approaches in melasma. Dermatol Clin. 2007;25(3):337-42. viii. doi: 10.1016/j.det.2007.04.006. [PubMed:17662899].

3. Vashi NA, Kundu RV. Facial hyperpigmentation: Causes and treatment. Br J Dermatol. 2013;169 Suppl 3:41-56. doi: 10.1111/bjd.12536. [PubMed: 24098900].

4. Olumide YM. Use of skin lightening creams. BMJ. 2010;341:c6102. doi: 10.1136/bmj.c6102. [PubMed: 21098586].
5. Taylor SC, Torok H, Jones T, Lowe N, Rich P, Tschen E, et al. Efficacy and safety of a new triple-combination agent for the treatment of facial melasma. Cutis. 2003;72(1):67-72. [PubMed: 12889718].

6. Khanna N, Rasool S. Facial melanoses: Indian perspective. Indian J Dermatol Venereol Leprol. 2011;77(5):552-63. quiz 564. doi:10.4103/03786323.84046. [PubMed: 21860153].

7. Lynde CB, Kraft JN, Lynde CW. Topical treatments for melasma and postinflammatory hyperpigmentation. Skin Therapy Lett. 2006;11(9):16. [PubMed: 17075653].

8. Ortonne JP, Arellano I, Berneburg M, Cestari T, Chan H, Grimes P, et al. A global survey of the role of ultraviolet radiation and hormonal influences in the development of melasma. J Eur Acad Dermatol Venereol. 2009;23(11):1254-62. doi: 10.1111/j.1468-3083.2009.03295.x. [PubMed: 19486232].

9. Kligman AM, Willis I. A new formula for depigmenting human skin. Arch Dermatol.1975;111(1):40-8. [PubMed: 1119822].

10. Grimes P, Kelly AP, Torok H, Willis I. Community-based trial of a triple-combination agent for the treatment of facial melasma. Cutis. 2006;77(3):177-84. [PubMed: 16610738].

11. Ball Arefiev KL, Hantash BM. Advances in the treatment of melasma: A review of the recent literature. Dermatol Surg. 2012;38(7 Pt 1):971-84. doi: 10.1111/j.1524-4725.2012.02435.x. [PubMed: 22583339].

12. Begum R, Rashid MM, Sikder A, Wahab MA, Chowdhury MAH. Triple combination agents for the treatment of facial melasma. Bangladesh J Dermatolol Venereol Leprol. 2008;25(1):13-5. 
13. Lin JY, Fisher DE. Melanocyte biology and skin pigmentation. Nature. 2007;445(7130):843-50. doi: 10.1038/nature05660. [PubMed: 17314970].

14. James WD, Berger TD, Elston DM. Andrew's diseases of the skin; clinical dermatology, disturbances of pigmentation. 11th ed. Philadelphia, USA: Saunders Elsevier; 2011.

15. Banker GS, Rhodes CT. Modern pharmaceutics. 2001. p. 299-301.

16. Akhtar N, Zaman SU, Khan BA, Haji M, Khan S, Ahmad M, et al. Evaluation of various functional skin parameters using a topical cream of Calendula officinalis extract. Afr J Pharm Pharmacol. 2011;5(2):199-206. doi: 10.5897/ajmr10.368.

17. Lachman L, Lieberman HA, Kanig JL. The theory and practice of industrial pharmacy.3rd ed. 2006. $535 \mathrm{p}$

18. United States Pharmacopeia (USP39); National Formulary (NF34). The United States Pharmacopeial Convention, Inc. 12601, Twin Brook Rockville MD 20852, antimicrobial effectiveness testing. 2016.111 p.

19. United States Pharmacopeia (USP39); National Formulary (NF34). The
United States Pharmacopeial Convention, Inc. 12601, Twin Brook Rockville MD 20852, antimicrobial preservative effectiveness testing. 2016. $117 \mathrm{p}$.

20. Bode S, Baert B, Vangele M, Lambert J, Burvenich C, Slegers G, et al. Stability of the OECD model compound benzoic acid in receptor fluids of Franz diffusion cells. Pharmazie. 2007;62(6):470-1. doi: 10.1691/ph.2007.6.6307.

21. Sanna V, Peana AT, Moretti MDL. Development of new topical formulations of diphenhydramine hydrochloride: In vitro diffusion and in vivo preliminary studies. Int J PharmTech Res. 2010;2:863-9.

22. Katzung BG, Masters SB, Trevor A. Basic and clinical pharmacology. 13th ed. San Francisco: Lange Basic Princibles; 2016.

23. Sweetman SC. Martindale: The complete drug reference. 38th ed. London; 2009.

24. Torok HM. A comprehensive review of the long-term and short-term treatment of melasma with a triple combination cream. Am J Clin Dermatol. 2006;7(4):223-30. doi:10.2165/00128071-200607040-00003. [PubMed: 16901182]. 